\title{
8
}

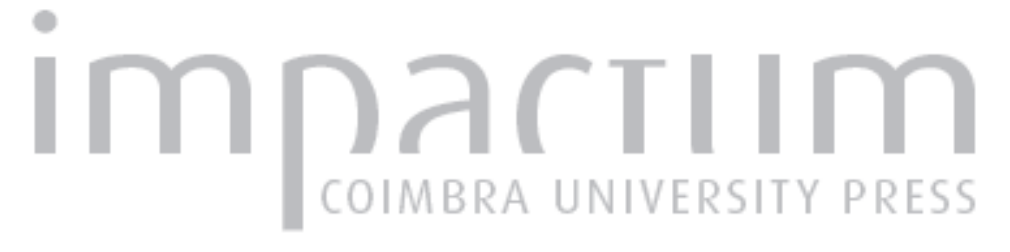

\section{Jacqueline de Romilly in Memoriam}

\section{Autor(es): $\quad$ Rodrigues, Nuno Simões}

Publicado por: Centro de História da Universidade de Lisboa

URL persistente:

URI:http://hdl.handle.net/10316.2/23649

DOI:

DOI:http://dx.doi.org/10.14195/0871-9527_21_16

Accessed : $\quad$ 26-Apr-2023 09:41:54

A navegação consulta e descarregamento dos títulos inseridos nas Bibliotecas Digitais UC Digitalis, UC Pombalina e UC Impactum, pressupõem a aceitação plena e sem reservas dos Termos e Condições de Uso destas Bibliotecas Digitais, disponíveis em https://digitalis.uc.pt/pt-pt/termos.

Conforme exposto nos referidos Termos e Condições de Uso, o descarregamento de títulos de acesso restrito requer uma licença válida de autorização devendo o utilizador aceder ao(s) documento(s) a partir de um endereço de IP da instituição detentora da supramencionada licença.

Ao utilizador é apenas permitido o descarregamento para uso pessoal, pelo que o emprego do(s) título(s) descarregado(s) para outro fim, designadamente comercial, carece de autorização do respetivo autor ou editor da obra.

Na medida em que todas as obras da UC Digitalis se encontram protegidas pelo Código do Direito de Autor e Direitos Conexos e demais legislação aplicável, toda a cópia, parcial ou total, deste documento, nos casos em que é legalmente admitida, deverá conter ou fazer-se acompanhar por este aviso.

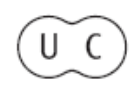



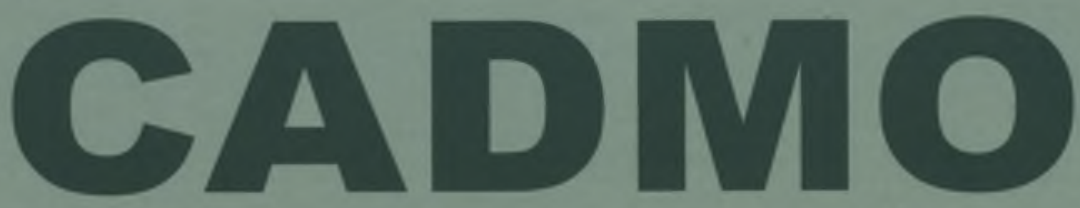

Revista de História Antiga

\author{
Centro de História \\ da Universidade de Lisboa
}

\title{
21
}

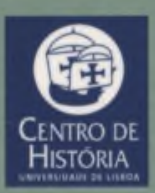

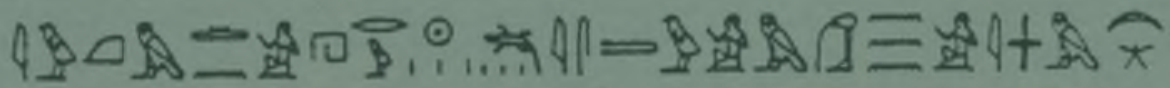

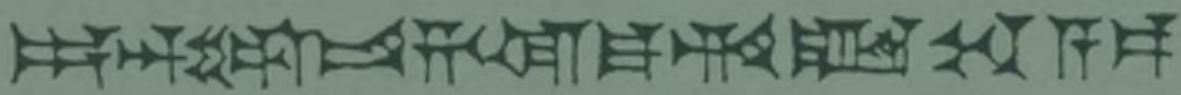

MHNIN AEI $\Delta \mathrm{E} \Theta \mathrm{EA}$ ПH$\Lambda \mathrm{HIA} \triangle \mathrm{E} \Omega$ 


\section{JACQUELINE DE ROMILLY IN MEMORIAM}

Jacqueline de Romilly nasceu em Chartres, em 1913. Oriunda de uma família judaica (tendo-se convertido ao catolicismo já no final da vida), Mme. de Romilly estudou no Liceu Molière, onde, em 1930, ganhou o Concurso Geral de Latim e recebeu o segundo prémio do de Grego. Frequentou depois o Liceu Louis-le-Grand, escola em que se preparou para ingressar na célebre Escola Normal Superior, em 1933. Em 1936, fez a Agregação em Clássicas, tendo alcançado o grau de Doutor em Letras em 1947. Durante a ocupação nazi, porém, e pelo facto de ter ascendência judaica, J. de Romilly foi suspensa da função pública pelo governo de Vichy.

Já licenciada e doutorada, Jacqueline de Romilly tornou-se professora na Universidade de Lille e mais tarde na Sorbonne, onde ensinou entre 1957 e 1973. Veio depois a assumir a cadeira de Grego, no Collège de France, tendo sido a primeira mulher a ser nomeada para esta prestigiada instituição. Em 1988, Jacqueline de Romilly protagonizou um novo acontecimento cultural em França, ao se tornar a segunda mulher, depois de Marguerite Yourcenar, a entrar na Academia Francesa, tendo sido eleita para a cadeira número 7 daquela associação, substituindo assim André Roussin.

O trabalho de J. de Romilly em prol da cultura e civilização gregas foi de tal modo reconhecido que, em 1995, o governo grego outorgou-lhe a nacionalidade helénica e, no ano 2000, tornou-se mesmo Embaixatriz do Helenismo, também por designação do Estado grego. Mme. de Romilly presidiu ainda à Associação Guillaume Budé, permanecendo como presidente honorária dessa conhecida instituição até à sua morte no final do ano 2010.

Dos muitos prémios que recebeu, destacam-se a "Grã-Cruz da Legião de Honra" (2007), a "Grã-Cruz da Ordem Nacional de Mérito", "Comandante da Ordem das Artes e das Letras", "Comandante da Ordem da Fénix» (Grécia), o "Prémio Onassis» (Atenas, 1995) e o «Prémio do 
Parlamento Grego". Foi-lhe ainda outorgado o grau de "Doutor Honoris Causa" pelas Universidades de Oxford, Atenas, Dublin, Heidelberga, Montreal e Yale. De referir ainda o facto de ter sido sócia correspondente das academias de Letras e Ciências de vários países, como a Dinamarca, a Grã-Bretanha, a Áustria, a Grécia, a Alemanha, a Itália, a Suiça e os Estados Unidos da América.

Para tema de doutoramento, Jacqueline de Romilly escolheu Tucídides, cuja obra traduziu para a conhecida colecção Budé, publicada pelas Belles Lettres. O historiador da Guerra do Peloponeso viria a ser, doravante, um dos seus pilares de referência e de estudo. A obra, Thucydide et l'impérialisme athénien, la pensée de l'historien et la genèse de l'œuvre, que viria a ser publicada pela mesma editora, tornar-se-ia um marco incontornável para qualquer estudo dedicado àquele historiador grego. A este estudo, seguir-se-iam outros dedicados ao pensamento historiográfico e político entre os Gregos, como Histoire et raison chez Thucydide (Belles-Lettres, 1956), La Loi dans la pensée grecque, des origines à Aristote (Belles Lettres, 1971), Problèmes de la démocratie grecque (Hermann, 1975), La construction de la vérité chez Thucydide (Julliard, 1990), Alcibiade ou les dangers de l'ambition (Fallois, 1995), L'Élan démocratique dans l'Athènes ancienne (Fallois, 2005), L'Invention de I'histoire politique chez Thucydide (ENS, 2005) e La grandeur de l'homme au siècle de Périclès (Fallois, 2010). A tragédia grega foi outro dos assuntos da predilecção da eminente Professora, como testemunham outras das suas importantes publicações, designadamente La crainte et l'angoisse dans le théâtre d'Eschyle (Belles Lettres, 1958), L'évolution du pathétique, d'Eschyle à Euripide (PUF, 1961), Le Temps dans la tragédie grecque (Vrin, 1971), La Modernité d'Euripide (PUF, 1986) e aquele que é considerado um dos seus estudos mais profundos, La douceur dans la pensée grecque (Belles Lettres, 1979). Dignos de menção são ainda Hector (Fallois, 1997), Héros tragiques, héros lyriques (Fata Morgana, 2000) e La Grèce antique contre la violence (Fallois, 2000).

Tivemos o privilégio de conhecer a Professora Romilly em 1998, num seminário organizado pela Fundação Calouste Gulbenkian, dedicado ao tema "Europa e Cultura». A apresentação da investigadora gaulesa, que na ocasião coube a outra eminente e prestigiada classicista, a lusitana Maria Helena da Rocha Pereira, proporcionou-nos, confessamo-lo, como decerto a qualquer outro aprendiz dos clássicos, a sensação de epifania olímpica.

A perspicácia e a argúcia científica, o rigor e a profundidade, a objectividade e ao mesmo tempo a paixão que Jacqueline de Romilly 
nutria pela Antiguidade Clássica em geral e pela Cultura Grega em particular - pelo pensamento político, pela memória, pela religiosidade, pela estrutura mental, pela construção de caracteres, pelas problemáticas da psicologia social, por temáticas como o medo, a angústia, a violência, o terror, a paz - são as características que mais facilmente se destacam dos textos de Mme. de Romilly. A prová-lo está a sua obra, que ficará como património de todos os que se interessam pelos mesmos temas que a ilustre Professora. Deixamos, por isso, como sugestão, a leitura de Pourquoi la Grèce? (Fallois, 1992), livro escrito com a maior elegância e leveza, e ao mesmo tempo rigor, próprios dos grandes sábios. Esta é, cremo-lo, uma leitura que facilmente converte ao classicismo até os que mais Ihe resistem.

Jacqueline de Romilly faleceu a 19 de Dezembro de 2010. Não só a França como a Europa e os Europeus, senão todo o Ocidente, ficaram substancialmente mais pobres.

Nuno Simões Rodrigues 